\title{
INÍCIO DA VIDA: AS FRONTEIRAS DO CONCEITO
}

\author{
Marcos de ALMEIDA', Daniel Romero MUÑOZ²
}

\begin{abstract}
"Ao destruir vida, não estamos destruindo algo intrinsecamente valioso. Este estado somente importa porque é necessário para outras coisas que importam por si próprias"

Johnathan Glover- "Causing deaths and Saving lives", 1984.
\end{abstract}

Almeida, M.; Muñoz, D.R. Início da vida: as fronteiras do conceito. Saúde, Ética \& Justiça, 4(1/2):1-6, 1999.

Resumo: O s autores discutem o conceito do início da vida contrapondo-o à questão do que torna a vida humana mais valiosa que outras formas de vida? Colocam que a vida é um "continuum" e que a emergência do indivíduo ocorre gradualmente até tornar-se o elemento vivo de maior significado moral: a pessoa. E buscam na conceituação de Locke os atributos que a tornam tão importante.

Unitermos: Aborto induzido. Bioética. Ética Médica. Fertilização. Vida.

\section{As fronteiras do conceito}

$\mathrm{A}^{\mathrm{a}}$ questão primordial para a Ética Médica, como de resto para a Ética de um modo geral é, também, em certo sentido, a primeira questão que surge quando começamos a lidar com os problemas morais da vida. A questão é simplesmente esta: o que torna a vida humana valiosa e, em particular, o que a faz mais valiosa que outras formas de vida? Não há dúvida de que avaliamos a vida humana de modo supremo; reputamos, logicamente, mais importante salvar uma pessoa do que um macaco (quando não podemos salvar a ambos) e consideramos correto agir assim. De fato, não julgamos a preferência pela vida humana como um mero pré-julgamento em favor da nossa própria espécie. Mas qual é a base dessa crença? O que a justifica? E o que, de algum modo, a torna mais do que simples vida, ou simples preconceito em favor de nós próprios e da espécie humana?

Esta questão - "o que torna a vida humana mais valiosa?" - pode parecer excessivamente abstrata e puramente filosófica. Interessante talvez, mas muito difícil e controversa para ser de alguma ajuda em resolver os problemas práticos que cada dia confrontam os profissionais de saúde. Todavia, ironicamente, muitas das decisões do dia a dia, tomadas na rotina da Medicina, da Enfermagem e mesmo de outras profissões da área da saúde, pressupõem respostas particulares precisamente a essa questão. $\mathrm{O}$ aborto, por exemplo, talvez fosse permissível, mesmo nos caso onde não existisse perigo para a mãe e

\footnotetext{
1 Professor Titular da disciplina de Medicina Legal e Bioética da Universidade Federal de São Paulo, UNIFESP.

${ }^{2}$ Professor responsável pelas disciplinas de Medicina Legal da Faculdade de Medicina da USP e Medicina Legal e Bioética da Faculdade de Ciências Médicas da Santa Casa de São Paulo. Laboratório de Investigação Médica, LIM - HC FMUSP.

Endereço para correspondência: Daniel Romero Muñoz. Rua Teodoro Sampaio, 115 . 05405-000 São Paulo.
} 
Almeida, M. \& Muñoz, D.R. Início da vida: as fronteiras do conceito.

ainda que o feto não fosse resultado de um estupro, na suposição de que o mesmo seria, de algum modo, menos valioso do que um adulto e, portanto, carecendo das proteções e direitos que este possue.

Imaginamos que a maioria das pessoas não acha que indivíduos desfavorecidos mental e fisicamente sejam, na realidade, menos valiosos do que outros. $E$, no entanto, qualquer um que considere que a descoberta de um defeito congênito, trissômico ou não, no feto é uma boa razão para o aborto, deve logicamente aceitar o fato de que tal indivíduo é, ou será, menos valioso do que outro sem tal defeito. Menos valioso porque menos habilitado para a vida e, conseqüentemente, menos merecedor de ser salvo ${ }^{1}$

O mesmo assunto de valor surge no outro extremo do continuum, onde perguntas são feitas no sentido de saber se devemos continuar a fornecer recursos para salvar e reanimar os excessivamente idosos, os terminais, aqueles em coma permanente e irrreversível, e assim por diante. Se nós decidimos contra a reanimação ou desviarmos recursos para casos mais compensadores, claramente estaremos tratando estas vidas como de menor valia, menos dignas de preservação do que as outras que escolhemos para ajudar.

As novas técnicas da embriologia "in vitro", que tornam possível o crescimento de embriões para fornecer tecidos humanos sob medida, nos dão razões adicionais para sermos claros acerca do valor relativo do embrião face ao adulto. Muitos acham que a resposta a essa questão poderia ser estabelecida se pudessemos estar seguros a respeito da questão relacionada: "quando começa a vida?". E, retornando à outra ponta do continuum, que nossos problemas com aqueles em estado vegetativo persistente estariam resolvidos se tivessemos uma adequada definição de morte.

A questão do início da vida tem sido debatida desde a antigüidade. Aristóteles afirmava que no concepto masculino a infusão do "Pneuma" ocor- ria em torno do $40^{\circ}$ dia após a coabitação do homem com a mulher; no concepto feminino a infusão só ocorria ao redor do $80^{\circ} \mathrm{dia}^{2}$. Santo Anselmo e Santo Agostinho assumiram esse ponto de vista e São Tomás de Aquino os seguiu, assegurando que a alma racional não é infundida no corpo a não ser algum tempo após a coabitação. Desse modo, os moralistas católicos usavam distinguir entre o "fetus inanimatus" (que ainda não recebera a infusão do "anima") do "fetus animatus" (que já recebera o "anima"), dizendo que não havia vida até o mexer-se ${ }^{3}$. Tais conceitos são, obviamente, muito discutíveis e sem qualquer embasamento científico.

$\mathrm{Na}$ verdade, ambas as perguntas - quando começa e quando termina a vida? - estão mal formuladas, ainda que a elas pudessem ser dadas determinadas respostas. O que precisamos saber não é quando a vida começa, mas sim quando a vida começa a importar moralmente. $E$ a questão correlata não é quando a vida termina, mas sim quando a vida cessa de ter importância moral. Resumindo: quando a vida principia a er aquele valor especial que, acreditamos, vai a ela se aderindo, e quando deixa de tê-lo?

Toda a questão de valorização da vida humana torna-se ainda mais clara, quando se observa o que dispõem os Códigos Penais de todas as nações do mundo, sem exceção. Em todos eles, a pena pelo crime de aborto, ou seja, a morte intencional intra-uterina do feto é invariavelmente, de monta consideravelmente menor que a pena pela morte de quem já nasceu, ou seja, pelo crime de homicídio. Qual a razão pela qual os juristas estabeleceram penas tão diversas?

Qualquer que seja o raciocínio que se utilize, não há como fugir à conclusão meridianamente clara de que para todos eles (os juristas do mundo inteiro) o homicídio é incomparavelmente mais grave do que o aborto. Ou, em outras palavras, a vida do feto que ainda não nasceu tem muito menor valia que a daquele que já nasceu!!! 
Almeida, M. \& Muñoz, D.R. Início da vida: as fronteiras do conceito.

\section{Conceito de início: momento $\mathrm{x}$ continuum}

Muitos supõem que a resposta à questão: quando a vida começa a importar moralmente? é a mesma resposta à questão de quando começa a vida humana. O momento da fecundação (concepção) aparenta ser a resposta óbvia para a pergunta. Sobre outras possíveis respostas tem a grande vantagem de que é um evento dramático e identificável, e um ponto a partir do qual o óvulo iniciaria o processo permanente que levaria à maturidade. Mas também é claro, embora menos dramático, que o óvulo já está vivo muito antes da concepção e, de fato, sofre um processo de desenvolvimento e maturação prévios, sem os quais a concepção é impossível. O espermatozóide também já está vivo e se contorcendo e também carece de desenvolvimento e maturação. Aliás, pela ordem de freqüência, as coisas que mais acontecem, quando da união do óvulo com o espermatozóide, são: em primeiro lugar rigorosamente nada, em segundo lugar aborto espontâneo, em terceiro lugar uma criança, e a seguir mola hidatiforme e coriocarcinoma, respectivamente.

Por outro lado já é possível dispensar o espermatozoide na produção de um novo ser, retirando o núcleo haplóide ( 23 cromossomas) do óvulo e colocando em seu lugar o núcleo diplóide (46 cromossomas) de uma célula somática, processo conhecido como "clonagem" ou partenogênese induzida. Frise-se que o processo natural de reprodução assexuada conhecido como partenogênese ou bipartição ocorre em um grande número de seres vivos, incluindo bactérias, protozoários, vermes insetos e crustáceos. "Segundo Maupas, a fecundação não é, de modo algum, uma condição geral e absoluta, requerida pela vida. Muitos animais e plantas multiplicamse sem fecundação. Deste modo, a fecundação é um processo complementar, secundário na reprodução, representando um caso particular na natureza da matéria animada". Aliás, Metalnikov demonstrou que os organismos unicelulares desconhecem a morte natural, uma vez que podem viver e multiplicar-se indefinidamente ${ }^{4}$.

A vida é um processo contínuo que prossegue ininterrupto de geração a geração. Não é, portanto, a vida que começa na concepção. Mas se não é a vida, não seria pelo menos um novo indivíduo que começa na concepção?

Em primeiro lugar, no caso da clonagem, o novo indivíduo prescinde de fertilização. Em segundo lugar, um certo número de "coisas" pode começar na concepção. A fertilização pode não resultar em um embrião, mas em coisa alguma, ou então em aborto expontâneo, ou em um tumor que eventualmente ameace a vida da mãe (uma mola hidatiforme ou um corioepitelioma). Este tumor presumivelmente, não estaria investido com qualquer dos direitos que, muitos acreditam, surgem "in concreto" no momento da fertilização.

Mesmo quando a fertilização está, por assim dizer, no caminho certo, não resulta de pronto em um indivíduo. O óvulo fertilizado torna-se um massa de células indiferenciadas que, eventualmente, divide-se em dois componentes principais: o embrioblasto e o trofoblasto. O primeiro resulta no feto e o segundo transforma-se nas membranas extra-embrionárias, na placenta e no cordão umbilical. Os derivados trofoblásticos são vivos, são humanos e têm, inclusive, a mesma composição genética do feto. $\mathbf{E}$ são desprezados por ocasião do nascimento 5 .

Uma complicação adicional é que o óvulo fertilizado não pode ser considerado um novo indivíduo, pois ele pode muito bem tornar-se dois, três ou mesmo quatro ou mais indivíduos. O óvulo fertilizado, como todos sabem, pode dividir-se e isto acontece até cerca de 15 dias após a fertilização.

A vida, portanto, é um continuum e a emergência do indivíduo ocorre gradualmente. Nesse ponto da argumentação é comumente alegado que, se a vida não começa na concepção e se não se pode dizer que um novo ser humano individualizado começa ali, pelo menos o potencial 
Almeida, M. \& Muñoz, D.R. Início da vida: as fronteiras do conceito.

para o novo ser humano está presente, com todo seu contingente genético completo e toda sua unicidade. E desde que o óvub fetilizado épotencialmente um ser humano, devemos atribuirIhe os mesmos direitos de que são possuidores os seres humanos completos. O Código Civil Brasileiro, aos moldes de outros códigos, normatiza que: “...a lei põe a salvo desde a concepção os direitos do nascituro".

Este argumento, embasado na potencialidade, segundo Harris ${ }^{7}$ sofre no entanto de vários tipos de dificuldade que the são fatais. O primeiro deles é o simples fato de que se algo inexoravelmente vai se tornar Zé (o que ainda assim não é o caso do óvulo fertilizado) isso não implica em que devamos, necessariamente, tratá-lo como se, de fato, ele já fosse Zé. Todos nós estaremos mortos inexoravelmente um dia, mas isto é (supomos) uma razão muito inadequada para nos considerar agora como se já fôssemos todos mortos.

Um segundo tipo de dificuldade com o argumento da potencialidade é o fato de se afirmar, por exemplo, que o aborto é errado porque uma pessoa que teria existido no futuro (e o exemplo de Beethoven é citado ad nauseam) não existirá se um aborto for realizado. Eu também não estaria aqui se minha mãe, quando grávida de mim, optasse pelo aborto. Mas eu também não estaria aqui se ela tivesse tomado um anticoncepcional eficiente. Nestes termos, quem for contra o aborto terá de sê-lo também contra a anticoncepção. E mesmo aqueles que são contra ambos (vamos deixar de hipocrisia), consideram iniludivelmente o aborto moralmente pior do que a contracepção; e o homicídio, por seu turno, pior que $o$ aborto.

Uma coisa, aliás, ressalta, como meridianamente clara, quando se analisa a legislação sobre o aborto em todos os países do mundo! É a nítida e insofismável valoração diversa que se atribui ao feto e à criança já nascida. É indisfarçável a idéia central de qualquer legislador sobre a face da terra no sentido de que a vida do feto tem menor valia que a vida do recém-nascido. De outro modo como poder-se-ia explicar a razão pela qual a pena para quem pratica o aborto é, invariavelmente, muito menor do que aquela aplicada a quem mata uma criança já nascida?

Se se está interessado na pessoa que virá, não fica clara que razão possa haver para pensar que terminar o processo é pior num estágio do que no outro. Afinal de contas, se estamos interessados no pudim é igualmente uma pena que ovos, leite e farinha sejam jogados fora antes ou depois de misturados (ou depois de já terem saído do forno!).

Outra dificuldade constitui-se no fato de que não é apenas o óvulo fertilizado que é potencialmente um ser humano. O óvulo não fertilizado e o espermatozóide são, da mesma forma, novos seres humanos em potencial. Dizer que um óvulo fertilizado é potencialmente um ser humano é apenas dizer que se certas coisas acontecerem (como a implantação uterina) e outras coisas não acontecerem (como aborto espontâneo), ele eventualmente tornar-se-à um ser humano. Mas a mesma coisa também vale para o óvulo não fertilizado e para o espermatozóide. Se certas coisas acontecerem com o espermatozóide (como encontrar um óvulo) e, além disso, certas outras coisas não acontecerem (como encontrar um DIU), então eles eventualmente tornar-seão um novo ser humano.

Tudo o que pode ser dito com segurança sobre o óvulo fertilizado é que se trata de tecido humano vivo. A vida de um novo indivíduo então, não começaria na fertilização, pois o óvulo e o espermatozóide são também vivos. A vida é um continuum e portanto, o que nós precisamos não 
Almeida, M. \& Muñoz, D.R. Início da vida: as fronteiras do conceito.

é de um conceito de quando a vida se inicia, mas de quando a vida começa a ter significado moral.

\section{Humano x pessoa}

Ao identificar as coisas que fazem a vida humana valiosa, estamos apontando para os aspectos que tornam valiosa a existência de qualquer ser que os possua. É importante ter uma palavra para tais seres que não seja simplesmente antropocêntrica ou específica da espécie. O termo pessoa se nos afigura como o melhor, qualquer que seja o aspecto que seu possuidor tenha. Embora o uso normal de pessoa seja apenas outro termo para ser humano no sentido neutro da espécie. Isso não dificulta necessariamente nosso entendimento normal da palavra como se poderia talvez imaginar. Por exemplo, a indagação de se existem ou não seres inteligentes e conscientes em outros planetas é uma questão nada absurda e perfeitamente normal. Se existem, não precisam ser seres humanos como nós, obrigatoriamente (aliás o surpreendente é que o fossem). O que importa, realmente, é, sob que aspectos (não físicos), nós somos como eles ou eles como nós?

Se pudermos responder a esta pergunta teremos esboçado um conceito de pessoa (e o que faz tais criaturas valiosas), de modo a que possamos aplicar tal conceito aos dilemas que nos confrontam diariamente e não ficarmos meramente à espera da resposta em algum futuro de ficção científica.

Porém, qualquer tentativa de traçar uma linha, a partir da qual se instala o estado de ser uma pessoa, tende a ser arbitrária por duas razões que estão relacionadas. Uma é que pessoa é conceito algo vago e extremamente fugidio. A outra é que a transição do óvulo fertilizado até o adulto, a exemplo de outros desenvolvimentos a nível biológico, pode ser melhor representada como uma curva suave para cima do que por uma sucessão de pequenos degraus abruptos. Perguntar: "quando" se começa a ser uma pessoa? É a mesma coisa que perguntar: quando começou a Idade Média? Ou indagar quais as razões lógicas (e biológicas) para afirmar que alguém no Brasil, com 17 anos, 11 meses e 29 dias não seja responsável criminalmente, embora no dia seguinte já o seja. O Código Civil Brasileiro estabelece que o nascimento com vida marca o início da existência da pessoa ${ }^{6}$, colocada pela nossa legislação penal como o elemento vivo de maior significado mo$\mathrm{ral}^{8}$. Linhas convencionais para propósitos sociais e legais, sempre podem ser arbitrariamente traçadas. Mas seria um equívoco grave se nós tomássemos as sombras projetadas por essas linhas com o fionteiasdefinitivas de uma realidade biológica e, pior ainda, como delineadoras de um conceito ético universal, a ser aceito por todos.

É portanto aceitável que, para efeito da construção de uma lei, os legisladores ponderem as diferentes opiniões e tracem, arbitrariamente, uma linha divisória. Seria, contudo, mais aceitável ainda (e mais próximo da realidade), se em vez de uma linha, fosse estabelecida uma faixa, que teria de ser suficientemente larga para ser abrangente e segura, e ao mesmo tempo estreita o bastante para poder ser útil e aplicável.

Não obstante, John Locke, na segunda metade do século XVII, formulou uma preciosa e elegante conceituação sobre pessoa, embora deva ser admitido que ele não procurava seres de outros planetas. O que ele tencionava era como distinguir pessoas de outras criaturas, de maneira que fizesse sentido a diferença de valor que nós colocamos nelas:

“... devemos considerar o que pessoa representa; que, eu penso, é um ser inteligente, pensante, que tem razão, reflexão e que se considera a mesma coisa pensante em diferentes ocasiões e lugares; que só opera por essa consciência que é inseparável do pensamento e parece-me essencial a ele; sendo impossível para qualquer um perceber o que ele percebe". 
Almeida, M. \& Muñoz, D.R. Início da vida: as fronteiras do conceito.

Almeida, M.; Muñoz, D.R. The beginining of life: the frontiers of conception. Saúde, Ética \& Justiça, 2(2): 1-6, 1999.

Abstract: The authors discuss the beginning of life conception, counter facing it to the question: what makes human life more valuable than other forms of life? They emphasise that life is a "continuum "and that human being turns on gradually until becoming morally the most significant living being: the person. Finally they try to find out in Locke's writings the reason why the person has such meaning.

Keywords: Abortion, induced. Bioethics. Forensic medicine. Fertilization. Life.

\section{Referências Bibliográficas}

1. Dworkin,G. Taking rights seriously. London, Ed. Duckworth, 1977.

2. Aristóteles. De animalibus. São Paulo, Atena, 1960.

3. Fletcher, J. Morals and medicine. Princeton, Princeton Univ.ersity Press, 1979.

4. Metalnikov, S. A luta contra a morte. Saraiva, São Paulo, 1946.

5. Jones, Jr. H.W. The ethics of "in vitro" fertilization. In: E.; P., ed. Human conception "in vitro". London,
Academic Press, 1981.

6. Legislação Brasileira. Código civil. 26.ed. São Paulo, Saraiva, 1976.

7. Harris, J. The value of life: an introduction to medical ethics. London, Routledge and Kegan Paul, 1984.

8. Legislação Brasileira. Código penal. 24.ed. São Paulo, Saraiva, 1986.

9. Locke, J. Essay concerning human understanding London, Oxford University Press, 1994. 